\title{
STATCOM+BESS Modelling and Harmonic Analysis
}

\section{Document Version}

Accepted author manuscript

Link to publication record in Manchester Research Explorer

\section{Citation for published version (APA):}

Vilchis-Rodriguez, D., Ahmedi, A., Barnes, M., Shen, S., Wang, Z., \& Gao, S. (Accepted/In press). STATCOM+BESS Modelling and Harmonic Analysis. In IET (pp. 1-6)

\section{Published in:}

IET

\section{Citing this paper}

Please note that where the full-text provided on Manchester Research Explorer is the Author Accepted Manuscript or Proof version this may differ from the final Published version. If citing, it is advised that you check and use the publisher's definitive version.

\section{General rights}

Copyright and moral rights for the publications made accessible in the Research Explorer are retained by the authors and/or other copyright owners and it is a condition of accessing publications that users recognise and abide by the legal requirements associated with these rights.

\section{Takedown policy}

If you believe that this document breaches copyright please refer to the University of Manchester's Takedown Procedures [http://man.ac.uk/04Y6Bo] or contact uml.scholarlycommunications@manchester.ac.uk providing relevant details, so we can investigate your claim.

\section{OPEN ACCESS}




\title{
STATCOM+BESS MODELLING AND HARMONIC ANALYSIS \\ Damian S Vilchis-Rodriguez, ${ }^{1}$ Arsim Ahmedi ${ }^{1}$, Mike Barnes ${ }^{1 *}$, Shuhang Shen ${ }^{2}$, Zhongdong Wang ${ }^{2}$, Siyu Gao ${ }^{3}$
}

\author{
${ }^{1}$ Department of Electrical and Electronic Engineering, University of Manchester, Manchester, UK \\ ${ }^{2}$ College of Engineering, Mathematics and Physical Sciences, University of Exeter, Exeter, UK \\ ${ }^{3}$ National Grid, Warwick Technology Park, Gallows Hill, Warwick, UK \\ *mike.barnes@manchester.ac.uk
}

Keywords: STATCOM, BESS, PQ Control, VSC

\begin{abstract}
In this paper, concepts of Static Compensator plus Battery Energy Storage System (STATCOM+BESS) operation, power control and modelling are reviewed. An implementation in Matlab-Simulink, considering a two level VSC based STATCOM+BESS is realized. Details of the implementation are provided and simulation results are presented. A single, aggregated 50 MVA BESS with the STATCOM connected to an external grid, is considered in the assessment. Harmonic propagation analysis is conducted by considering THD values at the point of connection of the STATCOM+BESS station.
\end{abstract}

\section{Introduction}

A STATCOM's primary function is normally to regulate reactive current flow by absorbing and injecting reactive power at the Point of Connection (POC). In essence, the STATCOM consists of an AC/DC power electronic inverter (realised using fully controllable switches) which can inject or absorb reactive power from the network, Fig. 1. Compared to other options for reactive compensation, STATCOMs have a fast response time, some built-in overload capability and redundancy, very low maintenance requirements, and lower losses. Moreover, the STATCOM's reactive operation is independent of system voltage. In other compensation devices, such as the Static VAr Compensator (SVC), the current capability is diminished with decreasing system voltage, since these are impedance-based devices. Furthermore, the STATCOM can offer increased transient operation in both capacitive and inductive mode, while the SVC is able to do so only in the inductive region [1]. In initial implementations of the STATCOM, the DC link was varied with a fixed switching pattern to control the reactive power injected [2]. However, this type of DC voltage regulation is not used any more in modern voltage source converter (VSC) based STATCOMs. Instead, the STATCOM adjusts the switching pattern (modulation index) for better regulation of its output voltage waveform and power output. Thus, a STATCOM behaves as a synchronous compensator with no mechanical inertia and with better control options, therefore it is capable to respond much more rapidly in case of transient changes in the system.

When a reasonably sized DC power source (such as a BESS) is added to the STATCOM the operating modes are extended, allowing additional charging/discharging modes of the DC source, where the real and reactive power output can be controlled independently. The resulting modes of operation increase the range of support that the STATCOM provides to the power network. For instance, it has been demonstrated that the addition of a BESS can be used to improve the transient response and dynamic behaviour of the conventional STATCOM [2, 3], with benefits such as: oscillation damping and voltage fluctuation mitigation, providing energy at peak demand, enhancing transient and dynamic stability, providing fault ride-through capability, etc [2].

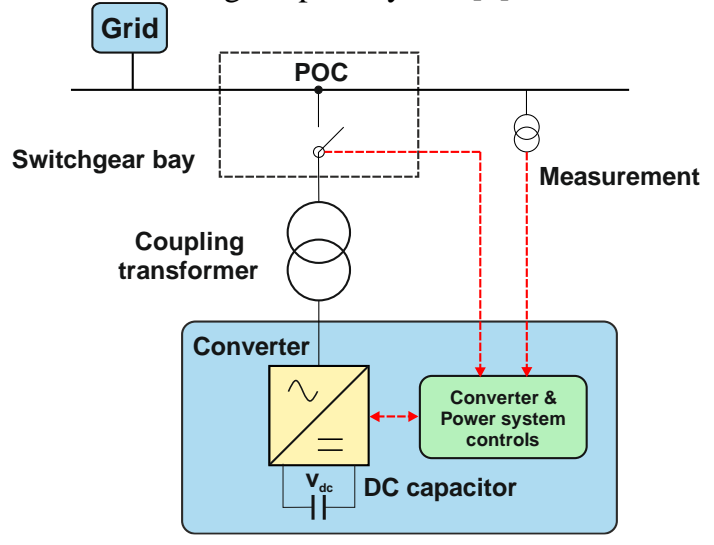

Fig. 1. Single line diagram of shunt connected STATCOM [2]

In this paper, concepts of the STATCOM+BESS operation and control are reviewed. An implementation in Matlab-Simulink is realized assuming a two level VSC based STATCOM+BESS. Details of the constituent model blocks are also included. STATCOM harmonic propagation analysis is conducted by considering THD values at the POC.

\section{STATCOM with real power capability}

In the ideal case, if there is no phase difference between the output voltage of the VSC and the AC system there is no real power transfer between them. When the VSC output voltage is lagging the $\mathrm{AC}$ system voltage, there is a real power flow from the network to the VSC: the VSC is operating in a rectifier mode and the transferred power charges the DC side. On the 
other hand, if the VSC output voltage is leading the AC system voltage, then the VSC injects real power into the AC system thus operating in inverter mode. On the DC side, an equivalent current will be drawn from the DC source and the DC voltage will decrease. In practice, the decrease in DC voltage limits the real power output that the system can provide, and it depends on the size of the BESS. This change in DC voltage is also the limitation which sets why a STATCOM without a storage system cannot be used to provide both reactive and real power independently. If the storage system is not charged from an external source, the energy available in the storage system remains limited: a discharge into the power system (and losses) must be balanced by a charge from the power system at another time. On the other hand, reactive power control is achieved by using output voltage magnitude control of the VSC, with the reactive power flowing toward the node with the lower voltage magnitude.

To provide the necessary $\mathrm{AC}$ voltage output (as required to provide services such as power delivery, voltage control, or frequency response) the VSC can be structured in several control levels or loops, as shown in Fig. 2 [4]. The innermost loop in Fig. 2 (the voltage loop) synthetizes the AC voltage waveform that is requested by the higher loop(s). Hence, it takes a voltage set point reference signal and converts it to a physical output. This is done by converting the DC side voltage to the AC output by the suitable switching pattern of the VSC switches. For better performance, both in terms of switching losses and harmonic elimination properties, most of the converters implement PWM switching patterns.

The simplest PWM switching control is sine-triangle PWM [5]. Using the control signals, the PWM is defined by two variables: the amplitude modulation ratio (i.e. modulation index) $m_{a}$ and the frequency modulation ratio $m_{f}$. The amplitude of the VSC output can be controlled by controlling $m_{a}$, the ratio of the peak control signal to the peak triangular sampling signal:

$$
m_{a}=\frac{v_{\text {control }}}{v_{\overparen{\text { trl }}}}
$$

The modulation index value is usually between 0 and 1 - linear modulation. When $m_{a}>1$, the peak of the reference signal exceeds the peak of the triangle and this leads to overmodulation. Operation in over-modulation is not desirable, because it generates low order harmonics and no longer gives a linear relation between converter output voltage and reference control signal. Other methods have the same limitations: available DC voltage which limits AC voltage, and the switching frequency which sets speed of response and harmonics.

\subsection{Current control loop}

The current control loop is commonly implemented with $d q$ control in the synchronous reference frame. Moving to this reference frame turns voltages and currents, which have the same frequency as the AC network, into DC quantities. This is convenient for implementation of well-known control approaches such as PI controllers, which do not work as well with AC quantities. The VSC basic equivalent circuit is shown in Fig. 3. Three AC inverter output voltages connect through an inductance and a resistance per phase to the AC network. The resistance and inductance are typically that of the equivalent series impedance of the cable and/or connecting transformer. The voltage equations of the circuit in Fig. 3 can be written in matrix form as:

$$
\boldsymbol{e}_{a b c}-\boldsymbol{v}_{a b c}=\boldsymbol{R} \boldsymbol{I}_{a b c}+\mathbf{L} p \boldsymbol{I}_{a b c}
$$

where

$$
\begin{aligned}
& \boldsymbol{e}_{a b c}=\left[e_{a}, e_{b}, e_{c}\right]^{\mathrm{T}} \\
& \boldsymbol{v}_{a c b}=\left[v_{a}, v_{b}, v_{c}\right]^{\mathrm{T}} \\
& \boldsymbol{I}_{a b c}=\left[i_{a}, i_{b}, i_{c}\right]^{\mathrm{T}} \\
& \boldsymbol{R}=\operatorname{diag}\left[R_{a}, R_{b}, \boldsymbol{R}_{c}\right] \\
& \boldsymbol{L}=\operatorname{diag}\left[L_{a}, L_{b}, L_{c}\right]
\end{aligned}
$$

And $p=\mathrm{d} / \mathrm{dt}$. After transformation, and assuming a balanced symmetric system, the voltage equations in the $d q$ domain are:

$$
\begin{aligned}
& e_{d}=R i_{d}+p L i_{d}-\omega L i_{q}+v_{d} \\
& e_{q}=R i_{q}+p L i_{q}+\omega L i_{d}+v_{q}
\end{aligned}
$$

Implementing the voltage equations (3)-(4) and 'nulling' the cross-coupling terms the control of the separate $d$ and $q$ current loops can be designed using the simplified block diagrams shown in Fig. 4, where the $i_{d}$ current control loop is shown (the $i_{q}$ control loop has the same structure). Usually, for the current loop, a PI controller is implemented.

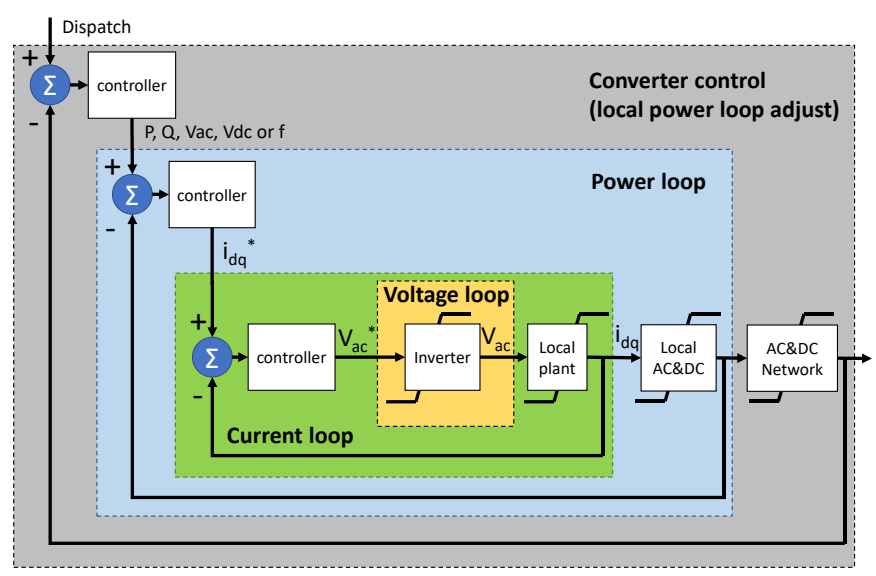

Fig. 2. Control loops of a VSC

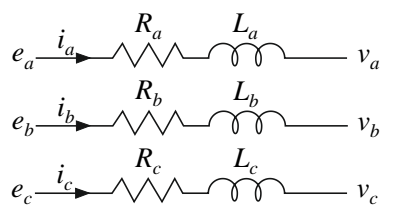

Fig. 3. Basic VSC equivalent circuit

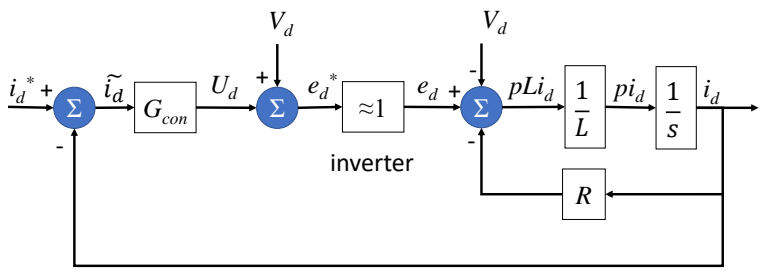

Fig. 4. Decoupled d-axis current control loop 


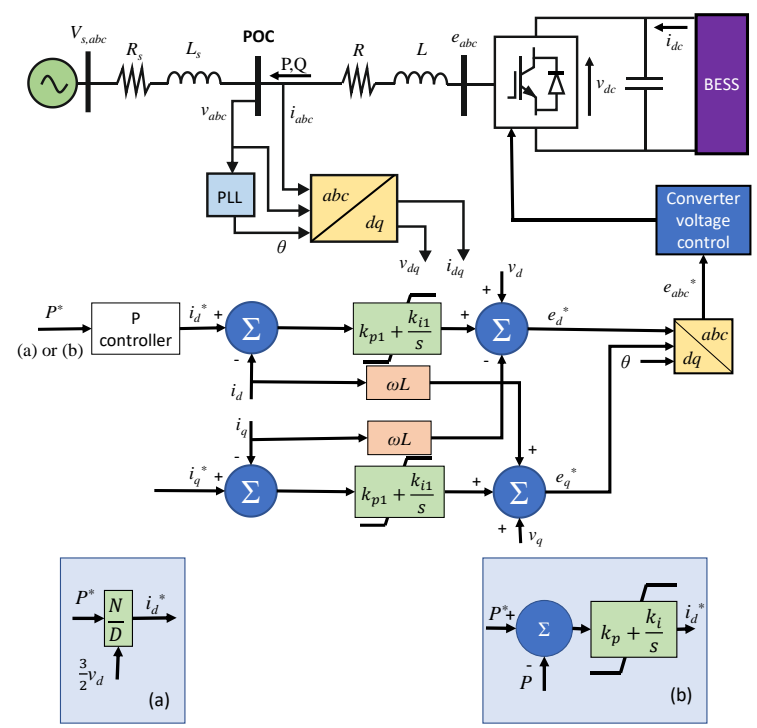

Fig. 5. Block diagram showing the current level control and real power reference signal [6].

The realisation of the current control in a real BESS system connected to the power network is shown in Fig. 5 [6]. It is shown that the reference value for the current $d$-axis loop is given by the outer real power control. The reactive power controller is added in the same manner on the $q$-axis loop. To realise the Park transformation correctly, it is important to know the phase of the grid voltage. For the control to work, whatever is governed by the control in the $d q$ domain, it has to correspond exactly with the physical quantities in the abc domain: the correct frequency $\omega$ in needs to be known, so that the $d q$ reference frame locks to the $V_{a b c}$ space-vector. For this reason, a key element added to this control level is another loop, which measures the phase angle (and frequency) of the grid voltage: the Phase Locked Loop (PLL). In this analysis the Simulink inbuilt PLL block is used for this purpose.

\subsection{Power loop}

From $d q$ theory, implementing the so-called 'magnitude invariant' Clarke transformation, the instantaneous real and reactive power using $d$ and $q$ components of voltages and currents can be written as (5), (6).

$$
p=\frac{3}{2}\left(v_{d} i_{d}+v_{q} i_{q}\right)(5) \quad q=\frac{3}{2}\left(v_{q} i_{d}-v_{d} i_{q}\right)
$$

To simplify the control even more, the axis can be aligned with $\boldsymbol{V}_{\text {abc }}$, which makes $v_{q}=0$. This decouples the real and reactive power control:

$$
p=\frac{3}{2} v_{d} i_{d}(7) \quad q=-\frac{3}{2} v_{d} i_{q}
$$

From (7)-(8) becomes evident that controlling the VSC's $d$ and $q$ output current, real and reactive power can be respectively controlled. For power control, feed-forward power loops are used in some cases. A feedback loop, which can be tuned to give a first or second order response, is used in other cases that require better performance. How both solutions could be added to the current loop is shown in Figs. 5(a)-(b) for the real power. The reactive power can be controlled in the same way using the $q$-axis current.

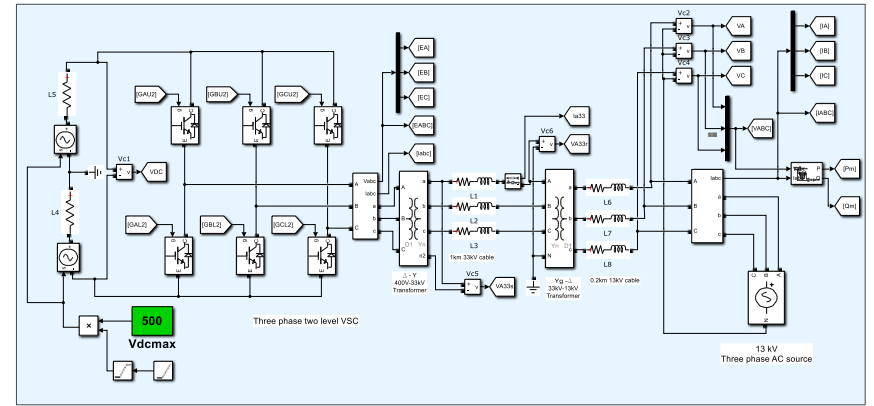

Fig. 6. Simulink STATCOM+BESS diagram

Table 1 Model components parameters

\begin{tabular}{ll} 
Component & \multicolumn{1}{c}{ Parameters } \\
Converter & $60 \mathrm{MVA}, 50 \mathrm{~Hz}, 400 \mathrm{~V}-33 \mathrm{kV}, \mathrm{L}_{\mathrm{m}}=23.48 \mathrm{H}, \mathrm{R}_{\mathrm{m}}=1.08 \mathrm{M} \Omega$, \\
Transformer & $\mathrm{R}_{400}=8.00 \mu \Omega, \mathrm{L}_{400}=0.75 \mu \mathrm{H}, \mathrm{R}_{33}=54.45 \mathrm{~m} \Omega, \mathrm{L}_{33}=5.10 \mathrm{mH}$ \\
\hline 33/13kV & $60 \mathrm{MVA}, 50 \mathrm{~Hz}, 33-13 \mathrm{kV}, \mathrm{L}_{\mathrm{m}}=25.88 \mathrm{H}, \mathrm{R}_{\mathrm{m}}=9.18 \mathrm{M} \Omega$, \\
Transformer & $\mathrm{R}_{13}=3.70 \mathrm{~m} \Omega, \mathrm{L}_{13}=0.54 \mathrm{mH}, \mathrm{R}_{33}=23.85 \mathrm{~m} \Omega, \mathrm{L}_{33}=3.45 \mathrm{mH}$ \\
\hline 33kV cable & $\mathrm{R}=13.57 \mathrm{~m} \Omega / \mathrm{km}, \mathrm{L}=108.23 \mu \mathrm{H} / \mathrm{km}$, Length $=1 \mathrm{~km}$ \\
\hline 13kV cable & $\mathrm{R}=13.77 \mathrm{~m} \Omega / \mathrm{km}, \mathrm{L}=101.32 \mu \mathrm{H} / \mathrm{km}$, Length $=0.2 \mathrm{~km}$ \\
\hline
\end{tabular}

\section{Simulink implementation}

Based in the approach described in section 2, a time step simulation of a STATCOM+BESS system, is implemented using Matlab-Simulink. The block diagram of the ensuing STACOM+BESS system is shown in Fig. 6. The system consists of a two level VSC based STATCOM, realised using ideal IGBT modules with an on-state resistance of $20 \mu \Omega$. The VSC is connected in parallel to a DC source operating at a maximum voltage Vdcmax, emulating a large BESS. A small $2 \mathrm{~m} \Omega$ series resistor is connected to the DC source to emulate the BESS internal resistance. The converter is connected through a $400 \mathrm{~V} / 33 \mathrm{kV} \Delta$-Y transformer to a series $\mathrm{RL}$ impedance, which represents a $1 \mathrm{~km}$ length, $33 \mathrm{kV}$ AC cable. The in-built Simulink, three-phase two windings, transformer model is considered in the simulations. The other end of the impedance is connected to a $33 / 13 \mathrm{kV}, \mathrm{Yg}-\Delta$ transformer. The $\mathrm{LV}$ side of the $33 / 13 \mathrm{kV}$ transformer is connected to another series RL impedance, which represents a 200m, $13 \mathrm{kV}$ AC cable. A three phase AC source, which emulates the network grid is connected at the other end of the circuit. Phase voltages and currents and active and reactive power are measured in the AC source terminals for control purposes. It is therefore assumed that the STATCOM+BESS systems should deliver the requested power at the terminals of the three-phase source. To avoid a large transient at the start of the simulation, the voltage sources are programmed to reach their nominal value following a predefined ramp function. In the simulations the power transfer stars after a few ms, to allow the ramp voltage to reach rated value. The model parameters are listed in Table 1 for completeness.

The angle, required to convert the phase variables to $d q$ quantities, is estimated using a built-in PLL block. The PLL block uses as input the grid side voltages, thus turning $V_{q}=0$, as mentioned in section 2 . To be consistent with the $d q$ axis alignment assumptions made in section 2, $\pi / 2$ radians are subtracted from the angle estimated by the PLL. For 
consistency with the discrete time solver used for the system numerical solution, discrete versions of the PLL and PI controller blocks are used in the model. To minimize delays in the control chain, the cosine and sine of the reference angle are calculated just once per time step and the values stored for subsequent calculations. It should be noted that calculation of trigonometric functions values is a relatively expensive task in term of computing time [7]. Once the reference angle is known, the phase quantities are transformed to the $d q$ domain; a two-stage process is used in the transformation. First the phase values are transformed to the $\alpha \beta$, stationary reference frame and in a second stage these are converted to $d q$ quantities. This approach allows the intuitive use of the trigonometric function stored from the previous step. The PWM signal used to switch the IGBTs modules on/off is synthetized using the block shown in Fig. 7. In the figure the suffixes $U$ and $L$ on the output signals stand for upper and lower, in reference to the upper and lower arms of the phase legs. As shown in the Fig. 7, the triangle (carrier) signal is appropriately scaled by the DC link voltage to allow a direct comparison with the reference signals. An example of the converter voltage signal resulting from the synthesised switching pattern is shown in Fig. 8. Clearly, high order harmonic voltages result from this process.

Once the required $d q$ quantities are known, instantaneous active and reactive power can be calculated using (5)-(8). The STATCOM+BESS PQ control can now be realized. Fig. 9 shows the $\mathrm{P}$ control block diagram for the system, considering the cascaded scheme depicted in Fig. 5b. The cascade controllers are designed in such a way that the power controller response is much slower that the inner current controller loop, preventing interference. For Q control a similar structure (not shown) is used. The response of the STATCOM+BESS system to a set of arbitrary PQ request is shown in Fig. 10. The voltage angles for the converter and grid sides corresponding to the three possible $\mathrm{P}$ transfer regimes are shown in Fig. 11. As can be seen in Fig. 10, the STATCOM+BESS system is capable to deliver active and reactive power independently and effectively.

\section{Harmonic propagation}

The harmonic spectrum for a two-level PWM controlled converter is shown in Fig. 12. For the sine-triangle PWM the output voltage harmonics will occur at frequencies $f_{h}$ :

$f_{h}=\left(j m_{f} \pm k\right) f_{1}$

In (9), the product of the modulation index $m_{f}$ and fundamental frequency $f_{1}$ equals the switching frequency $f_{s w}$. The modulation index $m_{f}$ is defined by the ratio of the switching frequency (i.e. triangle wave frequency) $f_{s w}$ and fundamental frequency (i.e. control waveform frequency) $f_{l}$. Coefficients $j$ and $k$ are integers, with the condition that when $j$ is odd, $k$ is even - thus the 'sidebands' of harmonics occur in even offsets for odd multiples of $m_{f}$, and sidebands occur in odd offsets for even multiples of $m_{f}$, as shown in Fig. 12. For a higher quality of output waveform, $m_{f}$ should be an odd integer value greater than 21 and ideally a multiple of three [5]. For the analysis THD voltage distortion is calculated using (10).

$$
T H D=\sqrt{\sum_{h=2}^{h=50}\left(\frac{V_{h}}{V_{1}}\right)^{2}} \times 100
$$

For THD measurement the IEC 61000-4-7 [8] is considered, thus it is assumed:

1. A 10 cycles (for $50 \mathrm{~Hz}$ systems) rectangular window for spectra analysis

2. No gap and no overlapping between successive measuring windows

3. $5 \mathrm{~Hz}$ frequency resolution

4. Harmonic subgroups are considered as per Fig. 13.

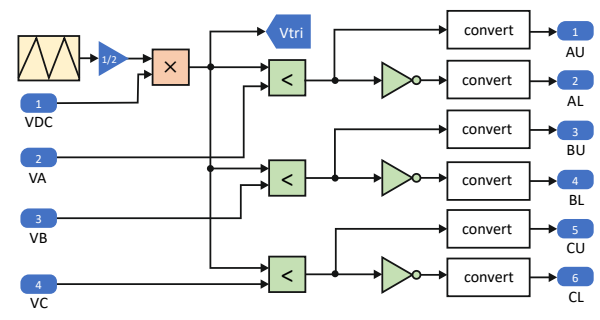

Fig. 7. PWM signal synthesizer

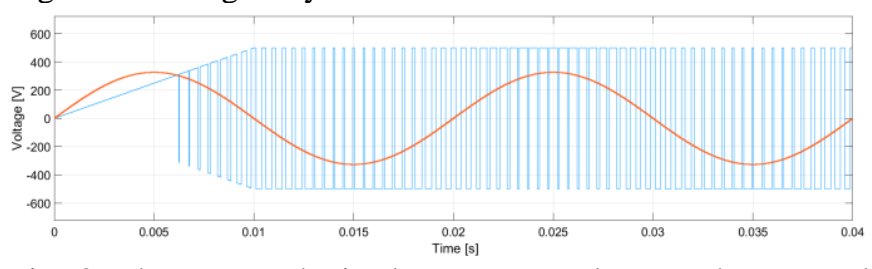

Fig. 8. Phase a synthetized converter voltage and measured grid side voltage.

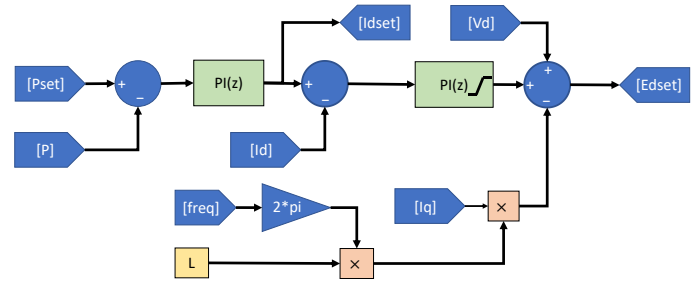

Fig. 9. Cascaded P control block

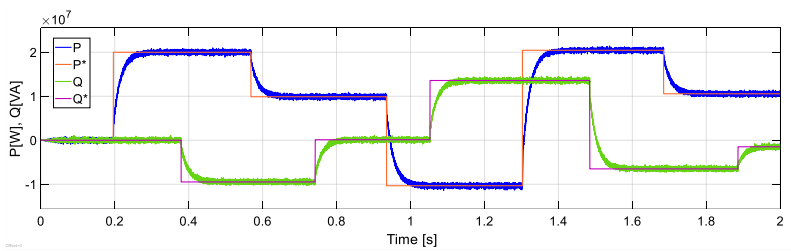

Fig. 10 STATCOM response to arbitrary P, Q requests

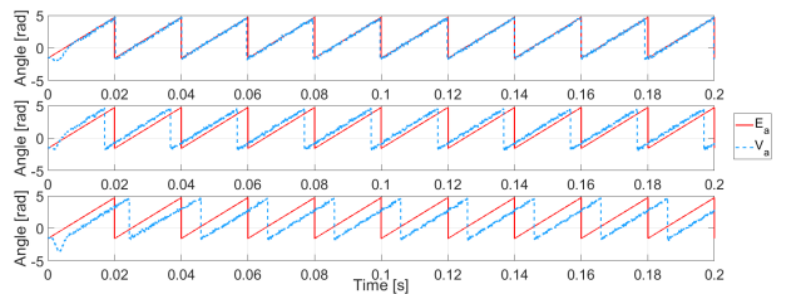

Fig. 11. Converter and grid side voltage angle for zero (top), positive (middle) and negative (bottom) $\mathrm{P}$ transfer regimes. 


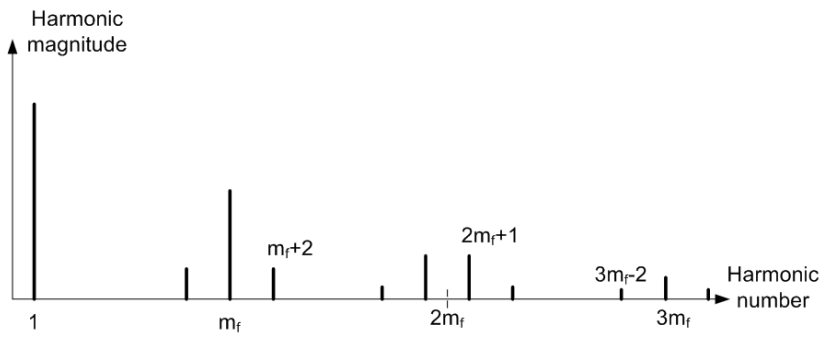

Fig. 12. Two-level converter harmonic spectrum for one phase at the converter terminal [4]

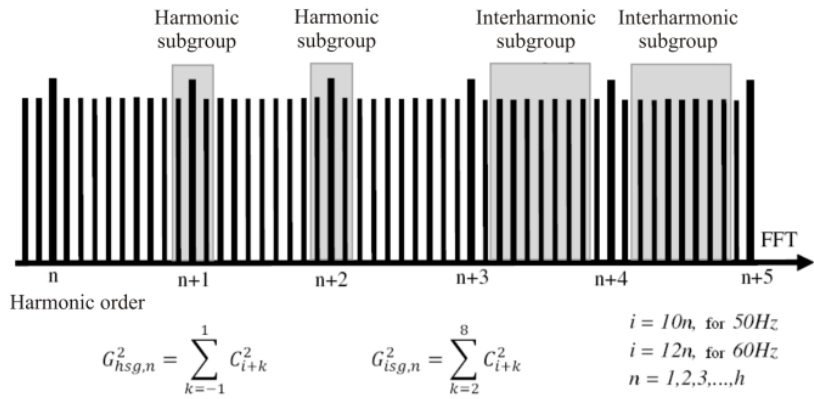

Fig. 13. Harmonics and inter-harmonics subgroups in accordance with IEC 61000-4-7 [9]

Figs. 14-15 show the THD values calculated for the converter terminals voltage (EA) for switching frequencies of 1650 and $1600 \mathrm{~Hz}$, respectively. As can be seen in the figures, the THD values are similar for both switching frequencies. The large THD values result from the high magnitude of the switching frequency component present in the corresponding voltage spectrum, as shown in Fig. 16. This component magnitude is in essence that of the BESS DC voltage.

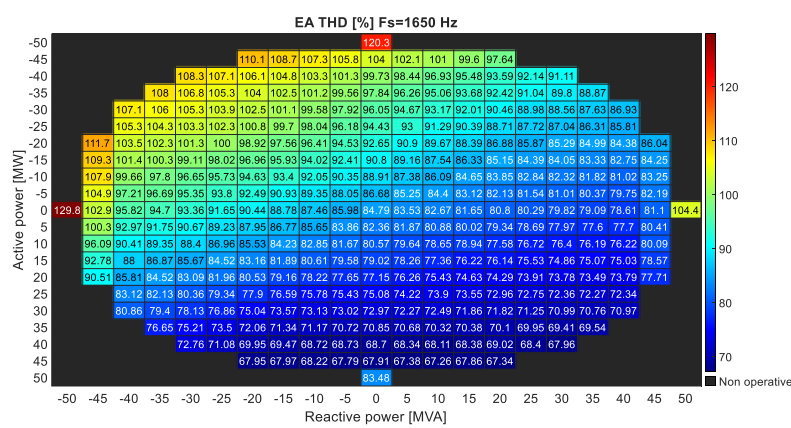

Fig. 14. THD voltage values at the converter terminals for a switching frequency of $1650 \mathrm{~Hz}$

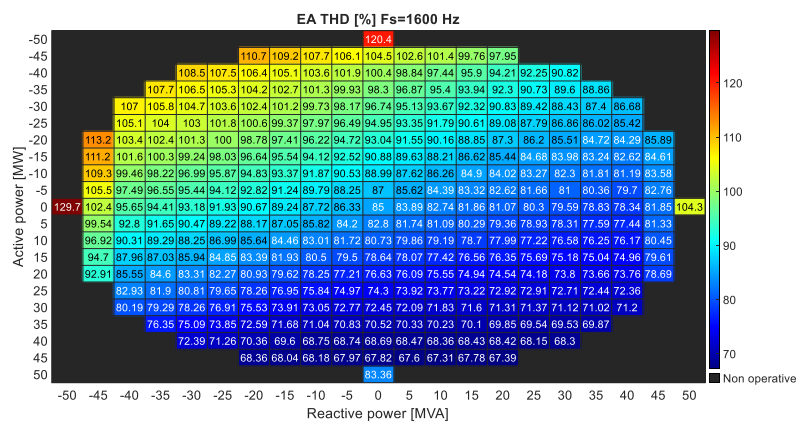

Fig. 15. THD voltage values at the converter terminals for a switching frequency of $1600 \mathrm{~Hz}$

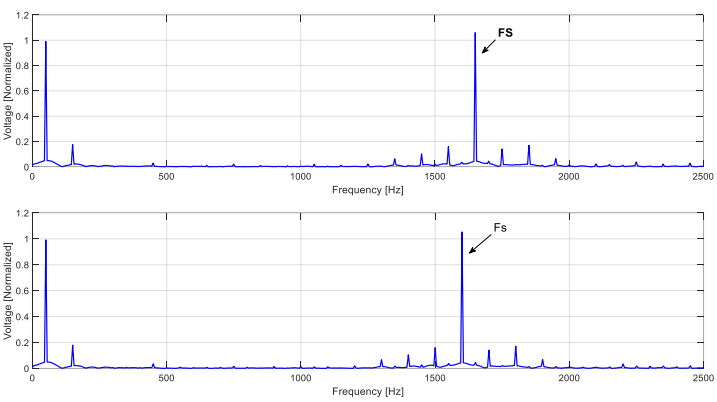

Fig. 16. Converter transformer terminal voltage frequency spectrum at $1650 \mathrm{~Hz}$ (top) and $1600 \mathrm{~Hz}$ (bottom) switching frequency

Figs. 17-18 show the THD voltage values on the HV side terminals of the converter transformer, for $1650 \mathrm{~Hz}$ and $1600 \mathrm{~Hz}$ switching frequencies, respectively. As can be seen in the figures, the THD values are substantially lower than that on the converter terminals. Furthermore, the THD values magnitudes are very similar for both switching frequencies for the same P-Q combinations. Thus, the use of an even or a triplen fundamental harmonic as switching frequency has no meaningful impact on the THD values for the cases analysed. This behaviour was further verified by considering more switching frequencies. Since in a three-phase balanced system a non-triplen harmonic is either a positive or negative sequence component, it could be intuitively assumed that a non-triplen switching frequency would have similar characteristics. Therefore, such a component would be expected to be capable of propagating further into the electrical network, through the converter transformer $\Delta-Y$ connection. However, such empirical expectation was found to be incorrect for the cases analysed.

Fig. 19 shows the HV side converter transformer voltage frequency spectrum for the 1650 and $1600 \mathrm{~Hz}$ cases. As can be seen in the figures, no significantly high frequency component at switching frequency exists in both spectra. Clearly, the converter transformer is blocking the switching frequency component. A detailed examination revealed that the switching frequency component present in the spectra of the converter voltages terminals were in-phase, thus behaving as a zero-sequence component. This behaviour was further verified for different switching frequencies within the $1-2 \mathrm{kHz}$ range, which is the expected switching frequency operating range for a converter with characteristics similar to the case here analysed. The phase angle of the switching frequency component present in the three phase voltages of the converter terminals are listed in Table 2. As can be seen in Table 2, the switching frequency component of the three phase voltages is in-phase, irrespectively of switching frequency value. This finding clarifies the limited harmonic penetration observed for the case under analysis, irrespectively of switching frequency. It should be noted that the observed behaviour may be specific to the analysed topology, thus further analysis are required to verify generality of the finding. Given that most of the voltage THD is produced by the converter switching frequency, the blocking effect of the converter transformer significantly reduces the THD at the point of connection. Thus no significantly high THD, or associated phenomena, is expected 
to occur at the POC as result of the converter operation, if an adequately configurated converter is used. This should be expected unless one of the generated converter harmonics sidebands hits one of the natural resonant frequencies of the converter transformer. For such kind of analysis a high frequency transformer model is required, such scenario is beyond the scope of this paper.

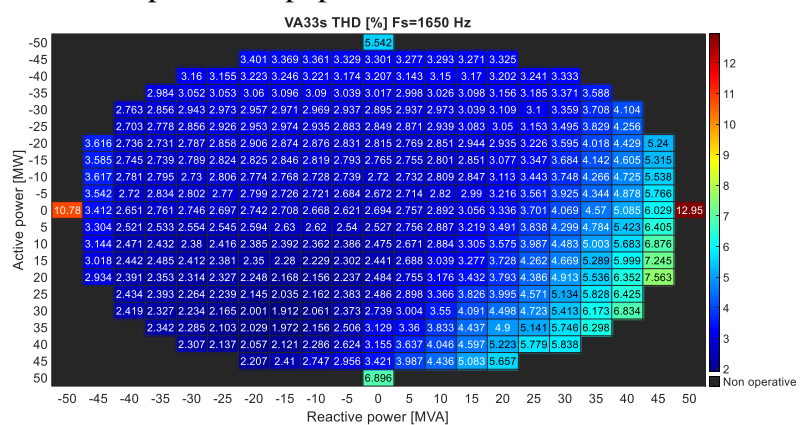

Fig. 17. HV side converter transformer THD voltage for a $1650 \mathrm{~Hz}$ switching frequency

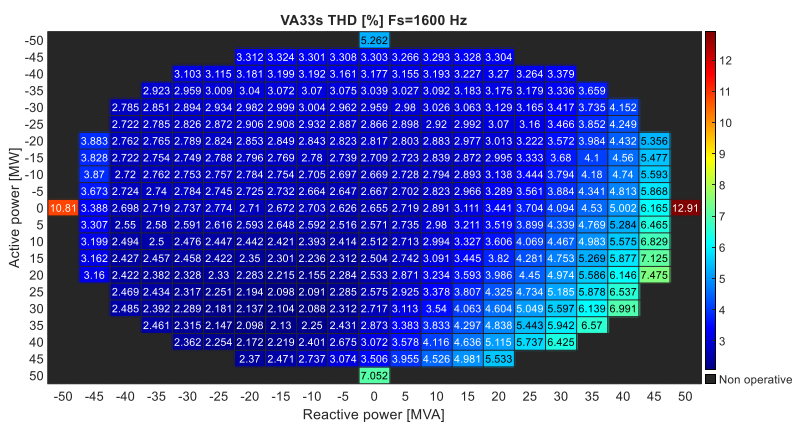

Fig. 18. HV side converter transformer THD voltage for a $1600 \mathrm{~Hz}$ switching frequency
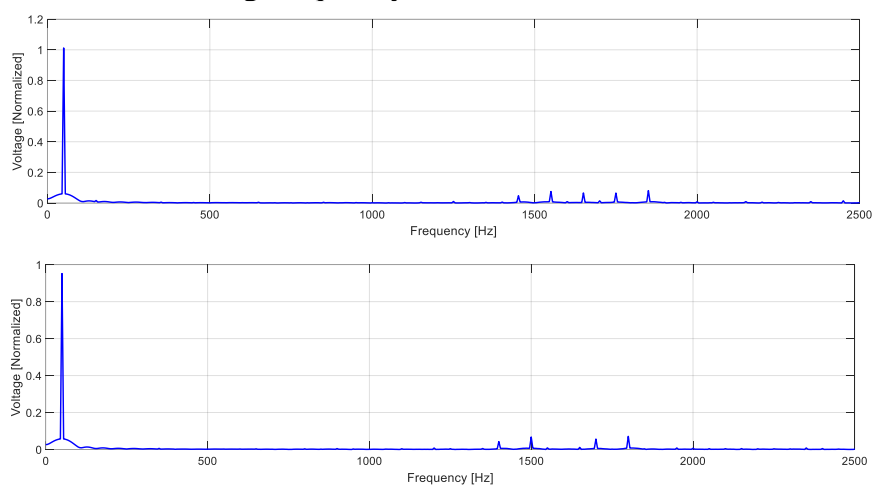

Fig. 19. Converter transformer HV side voltage spectrum for 1650 (top) and $1600 \mathrm{~Hz}$ (bottom) switching frequencies

Table 2 Switching frequency component phase angle at the converter terminals voltage

\begin{tabular}{cccc}
\hline $\begin{array}{c}\text { Switching Frequency } \\
\text { [Hz] }\end{array}$ & \multicolumn{4}{c}{ Converter phase, phase angle [Radians] } \\
\cline { 2 - 4 } & A & B & C \\
\hline 1000 & -3.02 & -3.03 & -3.03 \\
\hline 1050 & -3.02 & -3.02 & -3.01 \\
\hline 1350 & -3.04 & -3.04 & -3.04 \\
\hline 1400 & -3.04 & -3.02 & -3.02 \\
\hline 1600 & -3.03 & -3.03 & -3.03 \\
\hline 1650 & -3.03 & -3.03 & -3.03 \\
\hline 1950 & -3.04 & -3.04 & -3.03 \\
\hline 2000 & -3.04 & -3.03 & -3.03 \\
\hline
\end{tabular}

\section{Conclusion}

Concepts of the STATCOM+BESS operation, control and modelling were presented in this paper. An implementation of a STATCOM+BESS system in Matlab Simulink, assuming a two level VSC based STATCOM, connected to an external grid, is realized. Details of the model constitutive blocks are described. Effective and independent control of active and reactive power is demonstrated using cascaded PQ control. It was found that the main converter generated harmonics are zero sequence components. This harmonic characteristic, in combination with the $400 \mathrm{~V} / 33 \mathrm{kV} \Delta-\mathrm{Y}$ connected converter transformer, was found to offer an effective barrier to limit harmonic propagation of the very high harmonic content present in the STATCOM converter terminals, beyond the POC. THD analysis at the POC shows limited effect of the converter station in voltage quality. The presence of the STATCOM+BESS system is expected to have no negative impact in the power quality at the POC for the system assumed in this assessment.

\section{Acknowledgements}

This work was funded as part of the National Grid/NIA project "Power Electronics Enhanced Transformer", PEET.

\section{References}

[1] Erinmez, I., Foss, A.: 'Static Synchronous Compensator (STATCOM)', Report, Cigre Working Group 14.19, 2000.

[2] Chakraborty, A., et al.: 'Integrating STATCOM and battery energy storage system for power system transient stability: A review and application', Adv. Power Electron., 2012.

[3] Yang, Z., et al.: 'Integration of a StatCom and battery energy storage', Proc. IEEE Power Eng. Soc. Transm. Distrib. Conf., vol. 3, no. SUMMER, p. 1798, 2001.

[4] Holmes, D.G., Lipo, T.A.: 'Pulse Width Modulation for Power Converters: Principles and Practice', Piscataway, NJ, IEEE Press, 2003..

[5] Mohan, N., Undeland, T.M., Robbins, W.P.: 'Power Electronics-Converters Applications and Design', New York:Wiley, 2003.

[6] Wang, W., et al.: 'Analysis of active power control for VSC-HVDC', IEEE Trans. Power Deliv., vol. 29, no. 4, pp. 1978-1988, 2014.

[7] Vilchis-Rodriguez, D.S., Acha, E.: 'Nodal Reduced Induction Machine Modeling for EMTP-Type Simulations', in IEEE Transactions on Power Systems, vol. 27, no. 3, pp. 11581169, Aug. 2012.

[8] International Standard IEC 61000-4-7, 'Electromagnetic compatibility (EMC) - Part 4-7: Testing and measurement techniques - General guide on harmonics and interharmonics measurements and instrumentation, for power supply systems and equipment connected thereto', IEC, 2002-2008.

[9] Bečirović, V., et al.: 'Development of measurement system for analyzing the power quality', International Symposium on Power Electronics Power Electronics, Electrical Drives, Automation and Motion, Sorrento, 2012, pp. 1283-1289. 